\title{
Management of Pediatric Malaria: Role of Nutritional Interventions
}

\author{
Akoto Kwame Osei ${ }^{\mathrm{a}}$ Davidson H. Hamer ${ }^{\mathrm{a}, \mathrm{b}}$ \\ ${ }^{a}$ Tufts University Friedman School of Nutrition Science and Policy, and ${ }^{\mathrm{b} C e n t e r ~ f o r ~ I n t e r n a t i o n a l ~ H e a l t h ~ a n d ~}$ \\ Development, Boston University Schools of Public Health and Medicine, Boston, Mass., USA
}

\section{Key Words}

Malaria, children, treatment - Plasmodium falciparum •

Zinc $\cdot$ Iron $\cdot$ Vitamin A

\begin{abstract}
Malaria is a leading cause of morbidity and mortality among children, particularly in sub-Saharan Africa. Although substantial progress has been made in the treatment of pediatric malaria with artemisinin-based combination therapy, there remain many obstacles to the effective implementation of these highly efficacious new treatment options. Similarly, while effective tools are available for the prevention of malaria in children, scaling these up so that they have a clear impact on malaria-associated morbidity and mortality has presented significant challenges to public health officials. Host nutritional status influences the acquisition and potential severity of malaria infection. While there is substantial evidence that malaria contributes to impaired weight and height gain in children, the impact of undernutrition on malaria is complex. There is increasing evidence that supplementation with certain micronutrients may play a critical role in the prevention of malaria in young children. Micronutrient interventions such as zinc or vitamin A supplementation may help reduce the burden of disease due to malaria whereas others such as iron may exacerbate infection. Differences in study design, quality, intensity of malaria transmission, and other study site characteristics complicate the interpretation of the limited number of studies that have evaluated the impact of specific micronutrients for the treat-
\end{abstract}

ment and prevention of malaria. There has only been one trial to evaluate the use of zinc as an adjunct in the treatment of malaria and it failed to demonstrate any benefit of zinc in this role. This article reviews the clinical management of malaria in children, interactions between malaria and nutritional status, and the potential role of micronutrient supplementation for the prevention of clinical malaria episodes in young children, with a particular focus on whether each nutrient supplement improves or worsens malaria outcomes.

Copyright $\odot 2008$ Nestec Ltd., Vevey/S. Karger AG, Basel

\section{Introduction}

Approximately two billion people, roughly a third of the world's population, live in malaria-endemic areas [1]. Malaria is a leading cause of morbidity and mortality for many of these people, and imposes a substantial economic and social burden on these societies, particularly in sub-Saharan Africa. Of the four species of Plasmodia that cause human disease, Plasmodium falciparum causes the greatest burden of disease and death worldwide.

Though precise data are lacking, most estimates agree that malaria causes 800,000 to $1,000,000$ deaths per year $[2,3]$. The proportion of childhood deaths caused by malaria appears to have been rising during the last three decades [4]. Factors contributing to the high burden of malaria mortality in Africa include continued reliance on chloroquine (CQ) despite high rates of treatment failure [5-7], the widespread presence of highly competent vec-

\section{KARGER \\ Fax +4161306 1234 \\ E-Mail karger@karger.ch}

www.karger.com (c) 2008 Nestec Ltd., Vevey/S. Karger AG, Basel

0517-8606/08/0661-0031\$24.50/0

Accessible online at:

www.karger.com/ane
Davidson H. Hamer, MD, FACP

Center for International Health and Development

3rd Floor, Crosstown, 715 Albany Street

Boston, MA 02118 (USA)

Tel. +1 617414 1267, Fax +1 617414 1261, E-Mail dhamer@bu.edu 
tors in the Anopheles gambiae complex [8], and limited access to effective medical care.

A global model of the burden of malaria estimated that 2.2 billion people were at risk for infection with $P$. falciparum in 2002 and that this species was responsible for more than 500 million episodes of clinical malaria [9]. Young children and pregnant women are particularly vulnerable to malaria. An estimated 400-900 million episodes of fever occur annually in children in sub-Saharan Africa, of which approximately half are likely to be due to malaria [8, 10-12]. More than 75\% of these occur in children under the age of 5 years. Indirect effects of the heavy burden of malaria in African children include chronic anemia, impaired growth, and delayed cognitive development. Despite having multiple clinical attacks of malaria annually, only $1-2 \%$ of young children develop severe malaria [8]. Children who survive severe malaria are at increased risk of permanent deafness, mental retardation and other serious sequelae of cerebral malaria, and those with anemia severe enough to require transfusion are at high risk of contracting blood-borne viral infections, including human immunodeficiency virus (HIV).

$P$. falciparum infection during pregnancy increases the chances of fetal death, prematurity, intrauterine growth retardation, low birth weight, and maternal anemia [13]. In sub-Saharan Africa, malaria in pregnancy is estimated to contribute to about $19 \%$ of low birth weight, more than $20 \%$ of maternal deaths each year, and from 75,000 to 200,000 infant deaths [13-15]. This situation has been exacerbated by the HIV epidemic, since HIV-seropositive women have a greater risk of complications from malaria during the course of pregnancy $[16,17]$.

The social and economic burden attributable to malaria is not precisely known, but is believed to be substantial. Malaria is responsible for up to 45 million disabilityadjusted life years annually across Africa [18]. In economic terms, malaria may cost between 0.25 and $1.3 \%$ of a country's per-person GNP growth rate $[19,20]$. Indirect costs of malaria to society include poor educational performance of children, exacerbation of malnutrition, and anemia, which has a negative impact on the cognitive and physical capacity of both children and adults. Accordingly, effective interventions for the prevention, improved diagnosis and treatment of malaria are likely to produce significant benefits for afflicted populations by alleviating suffering, decreasing mortality, and reducing the socioeconomic burden of disease caused by this widespread parasitic infection. There is increasing evidence that certain simple micronutrient interventions may help reduce the burden of disease due to malaria in young children whereas others, especially iron, may exacerbate the disease.

\section{Clinical Manifestations of Malaria in Children}

Symptoms of malaria usually appear about 10-15 days after the bite of an infected mosquito. Prodromal symptoms may include malaise, fatigue, myalgias, arthralgias, headache, anorexia, and low-grade fever [21]. These may last for 2-3 days before an acute paroxysm occurs. An acute attack begins with a chill or rigors and then within 30-60 min, fever develops in association with tachycardia, profuse sweating, headache, malaise, and myalgias. Patients may also have nausea, vomiting, mild diarrhea, abdominal pain, flushed skin, and dry skin. High fevers last for several hours and then are followed by a period of intense sweating. As untreated infections progress, the spleen gradually enlarges and anemia worsens. There also may be hepatomegaly, orthostatic hypotension, mental confusion, and jaundice. Additional laboratory findings include thrombocytopenia, leukopenia, and proteinuria. Abnormalities of liver function tests may occur; these include serum transaminase elevations, hyperbilirubinemia, hypoalbuminemia, and prolongation of the prothrombin time.

\section{Severe Malaria}

Severe malaria occurs primarily in children infected with $P$. falciparum; it is rarely due to $P$. vivax. In regions of the world where falciparum malaria is endemic, severe malaria is predominantly a disease of young children from the first few months of life, when passively acquired maternal immunity wanes, up to the age of 5 years or higher, depending on the local intensity of transmission. Common clinical and laboratory manifestations of severe malaria in children include prostration, impaired consciousness, respiratory distress, recurrent convulsions, severe anemia (hemoglobin $<5 \mathrm{~g} / \mathrm{dl}$ or hematocrit $<15 \%$ ), hypoglycemia, metabolic acidosis, and, less commonly, circulatory collapse [22]. Additional manifestations that occur slightly less frequently in children than adults include hemoglobinuria, abnormal bleeding, jaundice, and pulmonary edema. Cerebral malaria, one of the more common and life-threatening manifestations of falciparum malaria, consists of disturbances of consciousness (ranging from confusion, delirium, and stupor to coma), seizures, abnormalities of muscle tone, retinal hemorrhages, and focal neurological deficits. Hypoglyce- 
mia may be present and should be tested for. Case fatality rates of $10-20 \%$ are common. Survivors may have longterm neurological sequelae.

Clinical and laboratory features associated with an increased risk of death among children with severe malaria include: hypoglycemia, depth of coma, witnessed seizures, respiratory distress, acidosis or increased plasma lactate concentrations, jaundice, elevated cerebrospinal fluid lactate concentration, papilledema, retinal edema, $>20 \%$ of parasites in peripheral blood film containing malaria pigment, and greatly increased concentrations of tumor necrosis factor $[22,23]$. A recent study in Ghana of children with severe malaria, with an overall fatality rate of $11.2 \%$, found that circulatory collapse, impaired consciousness, hypoglycemia, and malnutrition independently predicted death [24]. In the Ghanaian study severe anemia was the most common manifestation but it was not associated with an increased risk of mortality. While these factors predictive of malaria were mostly identified in studies of African children with severe malaria, a recent prospective study in Orissa, India, found slightly different predictors of death in children including respiratory distress, coma, multiorgan dysfunctions (involvement of $\geq 2$ organ systems), and hyperparasitemia [25].

\section{Malaria-Nutrition Interactions}

The interaction between malaria and nutrition is complex [26] and has been the subject of controversy since the early 1950s. Several studies have shown associations between malaria and protein energy malnutrition, poor growth and certain micronutrient deficiencies among children [27-30]. Moreover, studies of malaria prevention involving insecticide-treated bed nets or chemoprophylaxis have been associated with improvement in the growth and micronutrient status of children [31-34].

Despite clear evidence of the impact of malaria on the nutritional status of affected individuals, the effect of nutritional status on host resistance to the acquisition and progression of malaria is still not clearly defined. Of particular interest is whether undernutrition places individuals at increased risk for acquiring malaria or having more severe infections.

\section{Protein Energy Malnutrition and Malaria}

Earlier studies suggested that poorly nourished individuals were to some extent protected against malaria [35-40]. Hendrickse et al. [37] found that patients with clinical malaria characterized by high-density parasit- emia were more likely to be above the 10th percentile of weight-for-age than were those with a low-density parasitemia. Ahmad et al. [41] showed a positive correlation between the level of parasitemia and weight-for-age in children infected with either P. falciparum or P. vivax. Murray et al. [35] demonstrated that feeding malnourished famine victims resulted in increased occurrence of clinical malaria attacks including more cerebral complications. A study by Olumese et al. [42] in Nigeria also found worse outcomes in malnourished children who were being treated for cerebral malaria. In a more recent study from Papua New Guinea, stunting appeared to lower the risk of developing falciparum malaria [43]. These studies thus suggested that undernutrition, especially protein energy malnutrition, helps protect against malaria.

However, other studies have produced contrary results. Using a cross-sectional design, el Samani et al. [44] recorded malaria more often in malnourished than in adequately nourished Sudanese children. Cross-sectional studies from Tanzania [45], Chad [46], Zaire [47], and Kenya [30] confirm the greater risk of malaria among children with poor nutritional status. A longitudinal study from Vanuatu [48] supports the claim that malnutrition predisposes the host to malaria infection, although another prospective study from The Gambia found virtually no association between nutritional status and malaria susceptibility [49].

A more recent review of the malaria-nutrition literature [50] concluded that the earlier findings of a protective effect of malnutrition against malaria were mainly based on studies with several methodological shortcomings. Reappraisal of the data together with recent literature indicates that the effect of nutrition on host susceptibility to malaria is more complex and, in many cases, poor nutritional status predisposes the host to an increased risk of infection, symptomatic clinical malaria attacks, and a higher likelihood of mortality from malaria.

\section{Diagnosis}

Definitive diagnosis of malaria depends on identification of the parasite in Giemsa-stained blood smears. Both thick and thin smears should be evaluated. Thick smears are more sensitive for the detection of the parasite but are not useful for species identification. If the initial smears are negative but there is a strong clinical suspicion of malaria, they should be repeated in $6 \mathrm{~h}$. 
Newer rapid immunochromatographic tests that utilize antibodies, which recognize the histidine-rich protein or parasite lactate dehydrogenase, have been developed for the detection of $P$. falciparum. These tests are easier to perform than blood smears and have sensitivities of $90-95 \%$ when compared to blood smears although they tend to be relatively insensitive if parasite density is low (e.g. $<100$ asexual forms/ $\mu \mathrm{l})[51,52]$.

In many rural areas of sub-Saharan Africa and other malaria-endemic areas of the world, diagnostic tests are not available. The World Health Organization's Integrated Management of Childhood Illness (IMCI) guidelines recommend the treatment of all fevers in children under 5 years of age with antimalarial therapy in countries with endemic malaria [53]. According to IMCI, in high malaria risk areas any child with fever or a history of fever in the absence of signs of severe malaria is presumed to have uncomplicated malaria.

Diagnostic Challenges in Pediatric Case Management

A major challenge to malaria case management in children is the over-diagnosis and over-treatment of nonspecific illnesses as malaria $[54,55]$. Since most rural clinics lack the laboratory facilities to perform blood smears, the decision to treat for malaria is usually based on clinical findings. In addition, acute lower respiratory tract infections may easily be misclassified as malaria by the current IMCI guideline [56]. Presumptive treatment is less acceptable when the cost of new treatments such as artemisininbased combination therapy (ACT) is substantially higher than less effective therapies such as CQ. New diagnostics such as rapid antigen tests offer a potential means for providing healthcare workers with quicker and more accurate diagnosis of malaria $[51,57]$. With the availability of rapid diagnostic tests, it is possible that case management outcome goals might be reached at a lower cost by using these highly specific tests to improve the targeting of expensive combination therapy drugs. However, recent studies suggest that this relatively new diagnostic tool is not being effectively utilized as $30-50 \%$ of children with negative rapid diagnostic tests are still being treated with antimalarials and a substantial proportion are not being tested despite availability of the tests $[58,59]$.

\section{Treatment of Pediatric Malaria}

Several factors influence malaria treatment decisions. These include the severity of the infection, the child's age, degree of background immunity, other host factors that may impair immune function such as malnutrition or advanced HIV infection, local patterns of antimalarial drug resistance, availability of drugs, and the cost of antimalarial drugs [60]. The goal of therapy in children with uncomplicated malaria should be to cure the infection, i.e. to completely eradicate the parasite from the body so that there is no possibility of recrudescence of the infection [21].

The cornerstone of the Roll Back Malaria Program's coordinated efforts in Africa has been improved malaria case management [61]. Advocates of Roll Back Malaria suggest that such greatly strengthened case management could halve malaria mortality by 2010 . Success in strengthening malaria case management depends on progress in four areas: (1) effective therapy; (2) accurate and reliable diagnosis; (3) drug availability, and (4) disease recognition and appropriate drug utilization at the household and community level. Unfortunately, substantial gaps in understanding and application exist in each of these areas.

\section{Antimalarial Drug Resistance}

The clinical efficacy of CQ has declined during the last three decades in much of eastern and southern Africa [62]. Children were at increased risk of CQ treatment failure - the results of a multi-country malaria study demonstrated that younger age, higher initial temperature, and higher baseline parasitemia predicted early treatment failure and a higher probability of worsening anemia between admission and 7 or 14 days after treatment [63]. Due to increasing evidence of the failing efficacy of CQ, several countries substituted sulfadoxinepyrimethamine (SP) for CQ as their first-line antimalarial. It is of concern that in many of these countries the clinical efficacy of SP has declined rapidly [64], forcing many to change their national policies, replacing SP with ACT.

There is now general agreement that combinations of effective antimalarial agents should be used $[21,65,66]$. The WHO has recommended that ACT should be the preferred replacement for failing monotherapies [21]. Several different treatment options have been evaluated for the treatment of malaria in children in sub-Saharan Africa including the fixed dose combination Coartem ${ }^{\circledR}$ (artemether-lumefantrine), a co-packaged combination of amodiaquine and artesunate, and SP plus artesunate. In some parts of Africa and elsewhere, especially southeast Asia, mefloquine plus artesunate is the treatment of choice. Both have proven highly efficacious in phase III clinical trials in areas with moderate to high levels of SP 
or CQ resistance in Africa and Thailand [67-69]. While efficacious in research studies, the complexity of their dosing regimens leaves the effectiveness of ACT as firstline therapy unproven. Moreover, ACT is significantly more expensive than CQ or SP.

\section{Challenges in Implementation of ACT for \\ Uncomplicated Pediatric Malaria}

The implementation of effective case management with ACT faces a number of challenges, notably complex ordering and financing procedures, the need to train health workers and provide clear guidelines for their use, and their introduction into weak health systems commonly characterized by suboptimal drug management and clinical practices [70, 71]. Therefore, despite being promising, new ACT drugs might not reach patients who need them and if they do, the challenge remains to ensure adequate clinical practices. Several recent studies that have examined the operational use of ACTs following national policy change in Kenya and Zambia have identified serious deficiencies in the availability of ACT drugs and appropriateness of their use by health workers [72-74]. The results of these studies suggest that changes in clinical practices at the point of care will take longer than anticipated. Major challenges include the need to ensure a constant, uninterrupted supply of drugs to health facilities, program activities that withdraw ineffective medicines, train health workers in new guidelines, provide enhanced supervision, and constantly monitor ambiguities and buried messages in guidelines that affect correct prescription. There also is an urgent need to evaluate new, potentially less expensive and more effective approaches to changing clinical practice among health workers at the periphery of the health system.

\section{Specific Treatment Recommendations for Pediatric Malaria}

After making a species-specific diagnosis, treatment choices should be based on local resistance patterns and will depend on which antimalarial drugs are locally available. Children infected with $P$. vivax, $P$. ovale, or $P$. malariae should be treated with CQ (table 1). With the exception of certain parts of southeast Asia where CQ resistance has been described [75], CQ remains effective for the treatment of these three species. A 2-week course of primaquine should also be provided, after ensuring that the child does not have glucose-6-phosphate dehydrogenase deficiency, to eradicate hypnozoites from the liver in order to prevent relapses.
CQ remains effective for the treatment of $P$. falciparum in Central America, Mexico, Haiti, the Dominican Republic, and regions of the Middle East where malaria is endemic. However, in much of the world, CQ and SP resistance are widespread so ACT, quinine, or mefloquine should be used. While artemether-lumefantrine was initially used primarily for children weighing $>10 \mathrm{~kg}$, a recent multi-site study in Africa suggests that it is safe and efficacious for children weighing 5-10 kg [76]. Children with fever, especially $\geq 38.5^{\circ} \mathrm{C}$, should be provided with antipyretic drugs to avoid the development of febrile seizures. Although some studies suggested that paracetamol use resulted in prolongation of parasitemia, the WHO currently recommends its use in the management of febrile children with malaria [21]. Based on a limited number of studies of the effect of underlying malnutrition on $\mathrm{CQ}$, SP, doxycycline, and quinine, there does not appear to be any need to adjust their doses in children who are undernourished. Similarly, there are no data as yet in underweight or wasted children for any of the newer ACTs so the same dosages should be used as for well-nourished children.

\section{Role of Zinc as an Adjunct to Treatment of Malaria}

Building on the results of studies of diarrhea and pneumonia, which showed beneficial effects of zinc for decreasing the duration of illness, the use of zinc as an adjunct to the treatment of acute, uncomplicated falciparum malaria in young children was evaluated in a randomized, placebo-controlled, multicenter trial in Ecuador, Ghana, Tanzania, Uganda and Zambia [77]. Children $(n=1,087)$ between the ages of 6 months and 5 years with fever and $\geq 2,000 / \mu l$ asexual forms of $P$. falciparum in a thick blood smear were enrolled at these sites and randomized to receive zinc $(20 \mathrm{mg} /$ day for infants, $40 \mathrm{mg}$ / day for older children) or placebo for 4 days as well as CQ, the standard first line treatment for malaria in all these sites at the time of study initiation. There was no effect of zinc on median time to reduction of fever (zinc $=24.2 \mathrm{~h}$ vs. placebo $=24.0 \mathrm{~h} ; \mathrm{p}=0.37$ ), reduction of parasitemia by $>75 \%$ in the first $72 \mathrm{~h}$ (zinc group $=73.4 \%$; placebo group $=77.6 \% ; \mathrm{p}=0.11$ ), or hemoglobin concentration during the 3-day period of hospitalization or 4-week follow-up period. Although this study failed to demonstrate a beneficial effect of zinc as an adjunct to the treatment of malaria, it did clearly show the impact of inflammation caused by malaria-induced acute phase response on plasma zinc concentrations. There was a significant inverse association between the density of parasitemia and plasma zinc concentration [78]. Successful treatment of ma- 
Table 1. Treatment options for pediatric malaria

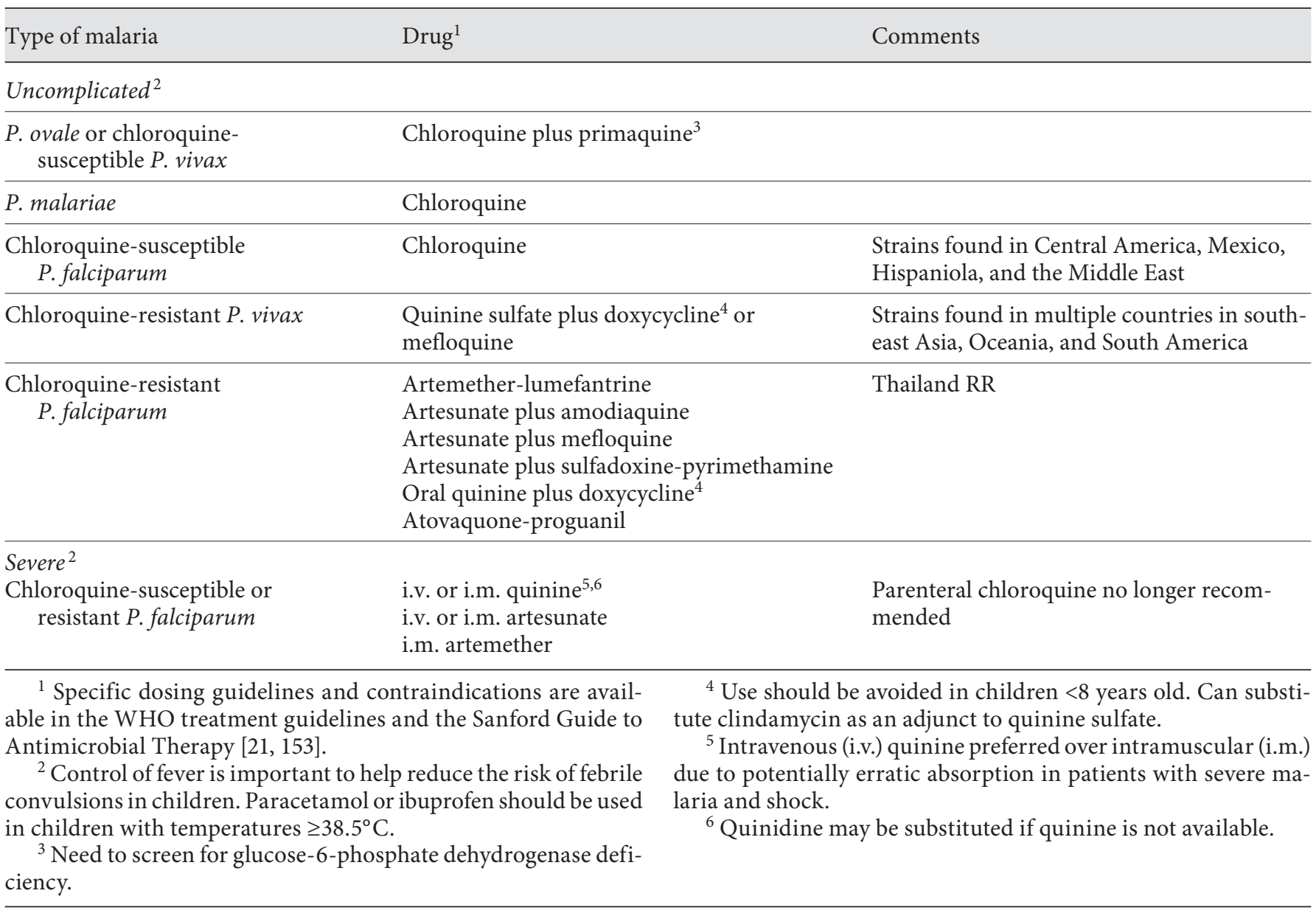

laria was associated with a significant rise in plasma zinc levels even in the absence of concomitant zinc supplementation.

\section{Management of Severe Malaria}

The main objective for the treatment of children with severe malaria is to prevent them from dying. Because death can occur within hours of reaching a health center, initial therapy should be both appropriate and aggressive to insure that therapeutic antimalarial concentrations are rapidly reached. Detailed information on the management of severe malaria can be found elsewhere [21, 22 ]. Fluid and electrolyte balance should be rapidly assessed and addressed. Therapeutic options are listed in table 1. One of the larger comparative studies found that treatment with parenteral artesunate was associated with a $37 \%$ reduction in mortality when compared to quinine [79]. Intramuscular artemether is an additional alterna- tive to quinine. In settings where parenteral therapy is not available, the use of rectal artesunate suppositories may be lifesaving $[21,80]$. Rectal artesunate is also useful as a bridge to oral therapy in children with uncomplicated malaria who are unable initially to take medications via the oral route.

\section{Supportive Measures in the Management of Severe Malaria}

Adjunctive measures play an important role in the management of children with severe malaria. Dehydration is common in children and must be rapidly but judiciously addressed in order to prevent acute renal failure from acute tubular necrosis [60]. Children with coma secondary to cerebral malaria should be evaluated for other potentially treatable causes of altered central nervous system status such as hypoglycemia and bacterial meningitis. These patients also need careful airway management to 
avoid aspiration. Seizures should be treated immediately with intravenous benzodiazepines or paraldehyde; rectal diazepam is an alternative if intravenous access is not available $[22,60]$. There is no proven role for ancillary treatment with heparin, cyclosporine, or corticosteroids.

Fever should be managed with mechanical measures such as tepid sponging, fanning or a cooling blanket as well as antipyretics such as paracetamol. Blood glucose should be monitored and hypoglycemia promptly treated. Fluid maintenance with a glucose-containing fluid may help to reduce the risk of hypoglycemia. Severe anemia, especially in children with concomitant respiratory distress, should be addressed by transfusion with fresh whole blood or packed red blood cells, adequately screened for blood-borne pathogens. Since bacteremia may occur in $5-8 \%$ of children with severe malaria [81], obtaining blood cultures and treating septicemia with appropriate antibiotics is critically important, especially in those with shock or metabolic acidosis. Patients with disseminated intravascular coagulation should be given vitamin $\mathrm{K}$ and transfusions with fresh, screened blood.

If the duration of coma is prolonged, i.e. more than 3 days, there is an increased risk of pneumonia. If a child with severe malaria acutely deteriorates, then hypoglycemia should be excluded, blood cultures obtained, and empirical therapy with broad-spectrum antimicrobial agents initiated. Parasite density should be monitored at least twice daily, and if the parasite count has not decreased by $75 \% 48 \mathrm{~h}$ after starting treatment, then an alternative antimalarial agent should be considered.

A limited number of studies have been performed to evaluate the pharmacokinetics of quinine in children with protein-energy malnutrition. Whereas one of these suggested a need for reducing the interval of administration of intramuscular quinine from 12 to $8 \mathrm{~h}$ [82], two other studies of oral and intravenous quinine, respectively, found several differences in the pharmacodynamics of quinine in malaria-infected and uninfected children with severe global malnutrition $[83,84]$. However, the authors of both studies concluded that there is no need for dosage alterations.

\section{Interactions between Specific Micronutrients and Malaria}

Most of the limited number of clinical trials that have evaluated micronutrients in children in malaria-endemic areas have involved supplementation trials for the prevention of malaria. In addition to the potential role of micronutrients, current and potential methods for controlling malaria include insecticide-treated materials (i.e. bed nets and curtains), mosquito larvae control, residual indoor insecticide spraying, genetically modified vectors, vaccines, and improved drugs for the treatment and prevention of malaria attacks [85]. The development and testing of an effective malaria vaccine is an important research priority though effective vaccines have so far proven elusive. The following section will provide an overview of a limited number of micronutrients that have been most intensively evaluated in relationship to malaria.

\section{Zinc}

Zinc is an essential trace element for cellular growth and differentiation $[86,87]$. Because of its critical role in cell division, zinc deficiency results in impaired immune function and reduced resistance to infections. Zinc deficiency has been hypothesized to exacerbate malaria infection [87] and there is mounting evidence that zinc supplementation could help to prevent malaria (table 2). A zinc supplementation trial in The Gambia found a 32\% reduction in health center visits for slide-confirmed malaria, though this difference did not attain statistical significance [88]. A 46-week period of supplemental zinc provided to preschool children in Papua New Guinea significantly reduced $P$. falciparum-attributable health center attendance by $38 \%(\mathrm{p}=0.037)$ [89] (table 2). Malarial episodes accompanied by any level of parasitemia were also reduced by $38 \%(\mathrm{p}=0.028)$ and episodes with parasitemia $\geq 100,000 / \mu l$ were reduced by $69 \%(p=0.009)$ in this study. In contrast, a community-based trial in Burkina Faso in which children aged 6-31 months were provided with either $12.5 \mathrm{mg}$ of supplemental zinc or placebo 6 days/week for 6 months failed to demonstrate any benefit of zinc on the incidence of clinical malaria episodes [90]. However, using baseline and end of study cross-sectional data, the mean density of $P$. falciparum parasites increased significantly $(\mathrm{p}=0.001)$ during the study in the placebo group relative to the zinc group. It is not clear why the incidence of clinical episodes of malaria was not affected by zinc in this study. Unlike the Gambia and Papua New Guinea studies, which used clinically confirmed malaria episodes as the primary outcome of interest, the Burkina Faso study used household surveillance for fever as an indicator of malaria episodes. Another possibility is that the sample size was too small to measure this effect, since the proportion of febrile malaria 
Table 2. Micronutrient supplementation trials and malaria prevention

\begin{tabular}{|c|c|c|c|c|c|c|c|c|}
\hline $\begin{array}{l}\text { Refer- } \\
\text { ence }\end{array}$ & $\begin{array}{l}\text { Study } \\
\text { site }\end{array}$ & Subjects & $\begin{array}{l}\text { Sample } \\
\text { size }\end{array}$ & Study design & $\begin{array}{l}\text { Treatment } \\
\text { groups }\end{array}$ & $\begin{array}{l}\text { Duration and } \\
\text { composition of } \\
\text { supplement }\end{array}$ & $\begin{array}{l}\text { Malaria } \\
\text { outcome }\end{array}$ & Magnitude of effect \\
\hline $\begin{array}{l}\text { Bates } \\
\text { et al. [88], } \\
1993\end{array}$ & Gambia & $\begin{array}{l}\text { Children } \\
(0.57-2.30 \\
\text { years })\end{array}$ & 110 & $\begin{array}{l}\text { Double-blind } \\
\text { placebo- } \\
\text { controlled trial }\end{array}$ & $\begin{array}{l}\text { Supplement } \\
\text { and placebo }\end{array}$ & $\begin{array}{l}70 \mathrm{mg} \text { zinc (as zinc } \\
\text { acetate or zinc } \\
\text { gluconate) twice } \\
\text { weekly for } 1.25 \text { years }\end{array}$ & $\begin{array}{l}\text { Malaria episodes } \\
\text { in clinic } \\
\text { attendance } \\
\text { records }\end{array}$ & $\begin{array}{l}32 \% \text { decrease in } \\
\text { malaria-related health } \\
\text { center visits }(\mathrm{p}>0.05)\end{array}$ \\
\hline $\begin{array}{l}\text { Shankar } \\
\text { et al. [89], } \\
2000\end{array}$ & $\begin{array}{l}\text { Papua } \\
\text { New } \\
\text { Guinea }\end{array}$ & $\begin{array}{l}\text { Children } \\
(6-60 \\
\text { months })\end{array}$ & 274 & $\begin{array}{l}\text { Randomized } \\
\text { double-blind } \\
\text { placebo- } \\
\text { controlled trial }\end{array}$ & $\begin{array}{l}\text { Supplement } \\
\text { and placebo }\end{array}$ & $\begin{array}{l}10 \text { mg zinc (as zinc } \\
\text { gluconate) daily } \\
\text { ( } 6 \text { days/week) for } 46 \\
\text { weeks }\end{array}$ & $\begin{array}{l}\text { Slide- } \\
\text { confirmed } \\
\text { malaria } \\
\text { episodes }\end{array}$ & $\begin{array}{l}38 \% \text { reduction in } \\
\text { malaria-related health } \\
\text { center visits in } \\
\text { treatment compared to } \\
\text { placebo }\end{array}$ \\
\hline $\begin{array}{l}\text { Muller } \\
\text { et al. [90], } \\
2001\end{array}$ & $\begin{array}{l}\text { Burkina } \\
\text { Faso }\end{array}$ & $\begin{array}{l}\text { Children } \\
(6-31 \\
\text { months })\end{array}$ & 709 & $\begin{array}{l}\text { Randomized } \\
\text { double-blind } \\
\text { placebo- } \\
\text { controlled trial }\end{array}$ & $\begin{array}{l}\text { Supplement } \\
\text { and placebo }\end{array}$ & $\begin{array}{l}12.5 \mathrm{mg} \text { (as zinc } \\
\text { sulfate) } 6 \text { days/week } \\
\text { for } 6 \text { months }\end{array}$ & $\begin{array}{l}\text { Slide- } \\
\text { confirmed } \\
\text { malaria } \\
\text { episodes }\end{array}$ & $\begin{array}{l}\text { No difference between } \\
\text { zinc and placebo groups } \\
\text { in the incidence of } \\
\text { falciparum malaria } \\
\text { (relative risk } 0.98,95 \% \\
\text { CI } 0.86-1.11 \text { ) }\end{array}$ \\
\hline $\begin{array}{l}\text { Binka } \\
\text { et al. [102], } \\
1995\end{array}$ & Ghana & $\begin{array}{l}\text { Children } \\
(6-90 \\
\text { months })\end{array}$ & 23,361 & $\begin{array}{l}\text { Randomized, } \\
\text { double-blind, } \\
\text { placebo- } \\
\text { controlled trial } \\
\text { in two sites }\end{array}$ & $\begin{array}{l}\text { Supplement } \\
\text { and placebo }\end{array}$ & $\begin{array}{l}30 \mathrm{mg} \text { (children aged } \\
6-11 \mathrm{months} \text { ) and } \\
60 \mathrm{mg} \text { (older children) } \\
\text { retinol equivalent as } \\
\text { retinyl palmitate in } \\
\text { purified peanut oil or } \\
\text { placebo for } 24 \text { months }\end{array}$ & $\begin{array}{l}\text { Fever episodes } \\
\text { and malaria } \\
\text { mortality rate }\end{array}$ & $\begin{array}{l}32 \text { and } 23 \% \text { decrease in } \\
\text { probable malaria illness }\end{array}$ \\
\hline $\begin{array}{l}\text { Shankar } \\
\text { et al. [109], } \\
1999\end{array}$ & $\begin{array}{l}\text { Papua } \\
\text { New } \\
\text { Guinea }\end{array}$ & $\begin{array}{l}\text { Children } \\
(6-60 \\
\text { months })\end{array}$ & 480 & $\begin{array}{l}\text { Randomized } \\
\text { double-blind } \\
\text { placebo- } \\
\text { controlled trial }\end{array}$ & $\begin{array}{l}\text { Supplement } \\
\text { and placebo }\end{array}$ & $\begin{array}{l}200,000 \text { IU of vitamin } \\
\text { A every } 3 \text { months for } \\
13 \text { months }\end{array}$ & $\begin{array}{l}\text { Slide- } \\
\text { confirmed } \\
\text { malaria } \\
\text { episodes }\end{array}$ & $\begin{array}{l}30 \% \text { reduction in febrile } \\
\text { malaria episodes } \\
36 \% \text { reduction in } \\
\text { parasitemia } \\
11 \% \text { reduction in } \\
\text { splenomegaly }\end{array}$ \\
\hline
\end{tabular}

episodes of all children with positive blood smears was quite small. Finally, the prevalence of clinical zinc deficiency in the population under study was too low. Using a cutoff point for zinc deficiency of $60 \mu \mathrm{g} / \mathrm{dl}$ [91], only a small proportion of these children were zinc-deficient at baseline, as the mean zinc concentration was $76.5 \mu \mathrm{g} / \mathrm{dl}$. Theoretically, zinc might have a greater effect on clinical disease if used in a population where zinc deficiency was widespread. In contrast to the earlier study [90], a more recent trial in a different region of Burkina Faso, which evaluated the combination of a single large dose of vitamin A and daily zinc supplementation, found significant reductions in clinical malaria episodes and a prolongation of time to first malaria episode [92].

Overall, the results of these studies suggest that zinc may play an important role in the prevention of malaria in young children. However, more research is needed to support this claim and to determine optimal methods for delivery of zinc to children in malaria-endemic areas.

\section{Vitamin A}

Vitamin A plays an essential role in cell division, immune response, vision, reproduction and general health of children [93]. Marginal vitamin A deficiency, a common condition among children in malaria-endemic areas, has been associated with an increased risk of morbidity and mortality from a wide range of infections, including measles, pneumonia, diarrhea and malaria [94]. Vitamin A may help reduce malaria-associated morbidity by virtue of its beneficial effects on immune function. Concentrations of retinol similar to those found in normal human serum reduced $P$. falciparum replication in one in vitro model [95] though this finding could not be replicated by a second group [96]. The vitamin A metabolite, 9-cis-retinoic acid, decreased the malaria-induced production of inflammatory cytokines, particularly tumor necrosis factor, and increased the clearance of $P$. falciparum-infected erythrocytes through upregulation of 
CD36 expression on human monocytes and macrophages [97]. Either mechanism could explain how vitamin A supplementation might attenuate malaria-related morbidity.

Data from observational studies have demonstrated a negative association between serum retinol levels and the extent of malaria parasitemia in children [98-101]. In one study, low baseline serum retinol concentrations were associated with an increased risk of parasitemia, whereas retinol levels were directly correlated with antibody titers to $P$. falciparum sporozoites in children under the age of 5 years [98]. The magnitude of depression of the serum retinol level was inversely proportional to disease severity and the density of parasitemia [102, 103]. Since treatment of malaria causes plasma retinol and carotenoid levels to rise $[99,104]$, the reduced retinol levels are thought to be at least partially due to the acute phase response to infection $[102,105]$. However, several factors make it difficult to study the association between retinol levels and disease outcomes. Inflammatory processes induced by febrile infections lead to increased excretion of retinol via urine, which may deplete retinol stores quickly [93]. This can perpetuate vitamin A deficiency in children even when supplements are provided, thereby making it difficult to infer cause and effect when conducting a supplementation study. Although the serum retinol level is commonly used as a surrogate marker of deficiency, its use as an indicator of vitamin A status in malaria-endemic regions is problematic because serum retinol concentrations decline during the acute phase response [99] making this a relatively insensitive measure of hepatic vitamin A stores [106]. Nevertheless, acute declines in retinol stores in children with marginal vitamin A status may result in actual clinical deficiency.

\section{Prevention of Malaria with Vitamin A}

\section{Supplementation}

Several studies have examined whether vitamin A might be beneficial in preventing malaria (table 2). Two randomized, placebo-controlled trials were conducted in Ghana (both reported in a single publication) [102]. While there was a reduction of 23 and $32 \%$ in the percentage of children with probable malaria illness (temperature $\geq 37.5^{\circ} \mathrm{C}$ and $\geq 4,000$ parasites/ $\mu l$ ) in the two trials [102], vitamin A had no clear impact on malaria parasitemia rates or parasite densities. However, the number of children with probable malaria was so small that this study lacked adequate power to demonstrate an effect of vitamin A on slide-confirmed malaria morbidity. Furthermore, these two trials made only limited use of slide-con- firmed longitudinal surveillance and instead relied on reported fever as an indicator of malaria [107], which is known to be unreliable as a surrogate marker for malaria [108]. Nevertheless, despite significant study limitations (i.e., small sample size for slide-confirmed malaria, insensitive markers of disease), this work suggested that vitamin A may reduce clinical illness and parasitemia rates. A subsequent placebo-controlled study of vitamin A supplementation in 480 children in Papua New Guinea generated stronger evidence of a benefit for vitamin $\mathrm{A}$ in the prevention of malaria. Vitamin A supplementation caused a $30 \%$ reduction in symptomatic episodes of falciparum malaria $(\mathrm{p}=0.0013)$, with a trend towards lower mean parasite density $(\mathrm{p}=0.093)$ and lower splenomegaly rates $(p=0.075)[109]$. This benefit was most evident in children aged 12-36 months. Children between 12 and 36 months also had 35\% fewer episodes of slide-confirmed falciparum malaria and a $68 \%$ lower parasite density than those in the placebo group.

In Tanzania, providing preschool children with vitamin A supplements every 4 months decreased the risk of death from malaria [110]. In a study of hospitalised children in Mozambique, giving a single dose of vitamin A to severe malaria patients produced a nonsignificant beneficial effect on hospital death rates [111]. There were, however, no significant effects on the duration of hospital stay, time to resolution of fever, clearance of parasitemia, or development of neurological sequelae.

In summary, there is evidence that vitamin A deficiency may exacerbate malaria and also that malaria itself potentially contributes to vitamin A losses and thus to deficiency. Vitamin A supplementation appears to provide consistent, albeit small, benefits to children in endemic areas by reducing their risk of malaria.

\section{Iron}

In malaria-affected regions of the world, both malaria and iron deficiency coexist and interact in a manner that is of great public health interest. An acute malarial episode causes anemia, mainly through decreased production of erythrocytes by the bone marrow due to suppression of erythropoiesis and increased hemolysis [112]. Malaria also contributes to iron loss by means of its immobilization in the form of hemozoin, increased urinary excretion [113], and decreased intake and absorption of dietary iron [114]. Whereas there is little question of the effect of malaria on anemia and iron status among children, there is still controversy regarding the impact of 
iron deficiency and/or iron supplementation on malaria incidence or progression from asymptomatic parasitemia to clinically apparent malaria. This controversy is of great interest to public health practitioners because, despite the proven efficacy by several studies that supplementary iron is critical in the prevention of anemia, there is still debate over the use of iron supplements in malaria-endemic areas because of the concerns that such measures may increase the susceptibility of individuals to malaria infection.

\section{Early Studies Suggesting Iron Supplementation Exacerbates Malaria}

In humans, the controversial role of iron in host resistance or susceptibility to malaria infection was brought to light as early as the 1970s. Masawe et al. [115] reported more frequent malaria in patients admitted with iron deficiency. In 1978, Murray et al. [40] found more episodes of malaria in iron-deficient Somali nomads in feeding camps after iron supplementation. In this placebo-controlled study, members of the iron-supplemented group $(\mathrm{n}=67)$ took $900 \mathrm{mg}$ of ferrous sulfate for 30 days and the placebo group $(\mathrm{n}=71)$ took 3 tablets of aluminum hydroxide daily for the same period. Active observation for episodes of fever, signs and duration of infections and parasites in blood revealed 13 cases of malaria in the iron group compared to only 1 in the control group, although no malaria was noted at the start of the study in either group. These attacks were presumed by the authors to be reactivations of infections as a result of the iron treatment. However, the study has been criticized as having a short duration, which might not have allowed sufficient time for the supplemental iron to elicit improvements in immune function to help ward off the malaria parasite. The study also had a relatively small sample size and the results could not be generalized because it involved a displaced population whose health status and other nutritional deficiencies, including iron, are very different from the general population.

In 1986, Oppenheimer et al. [116] noted that infants in Papua New Guinea with lower hemoglobin levels at birth were less likely to have malaria during the first year of life. The control subjects in this study were matched to the treatment subjects by age, sex and domicile and they received $3 \mathrm{ml}$ saline as placebo. The use of parenteral irondextran $(3 \mathrm{ml}$ per infant containing $50 \mathrm{mg} / \mathrm{ml}$ elemental Fe-Imferon) at 2 months of age resulted in an increased prevalence of malaria at the 6- and 12-month follow-up; the odds of malaria parasitemia were nearly twice as high in the iron group compared to the placebo group.

\section{Studies Suggesting No Harm from Iron}

\section{Supplementation}

Results from the studies described thus far suggest a potentially protective effect of iron deficiency against malaria infection and an exacerbation of malaria during iron repletion. However, several recent studies have not shown a harmful impact of iron supplementation. In a study in The Gambia, schoolchildren (5-14 years) without access to antimalarial drugs were given an oral multimicronutrient supplement including a high dose of iron [117]. Children in the treatment group $(n=200)$ were given a twice-weekly multi-micronutrient supplement or a placebo for 3 months. The micronutrient supplement was composed of $200 \mathrm{mg}$ ferrous sulfate, $15 \mathrm{mg}$ thiamine, 15 $\mathrm{mg}$ riboflavin and $500 \mathrm{mg}$ vitamin $\mathrm{C}$. There was no significant difference in malarial incidence between the groups, but there was a trend towards higher parasite counts in those receiving the active supplement, although this was not statistically significant. A 16-week study in Papua New Guinea did not show any adverse effects of oral iron supplementation [118]. In this study, prepubescent children $(\mathrm{n}=318)$ in 4 community schools, with hemoglobin levels of $8-12 \mathrm{~g} / \mathrm{dl}$, were randomly assigned to receive either $200 \mathrm{mg}$ ferrous sulfate or placebo twice daily at school. Treatment and control groups were matched for age, hemoglobin, and proportion of oval-shaped red blood cells. At the end of follow-up, there was no effect of iron supplementation on parasitemia, parasite density, levels of antimalarial IgG, spleen size, or reported episodes of malaria. The authors speculated that acquired immunity might have masked the effect of iron on malaria but the lack of effects may also be attributed to certain study design flaws. For example, episodes of illness were assessed by asking children who had been absent from school for some days whether they had been sick. This might have led to recall bias and non-random misclassification, which might have attenuated the effects observed. Moreover, malaria parasitemia was not constantly or actively assessed. Instead, it was done through cross-sectional surveys or when children reported illness at school. This approach might have resulted in missing some asymptomatic infections over time.

Menendez et al. [119] followed 832 infants identified at birth and gave them iron supplements from 8 to 24 weeks of life. In this factorial trial, children were assigned to receive 1 of 4 treatments: (a) daily iron $(2 \mathrm{mg} / \mathrm{kg}$ ) plus weekly Deltaprim ( $\mathrm{n}=213)$; (b) iron plus weekly placebo $(\mathrm{n}=$ 204); (c) daily placebo plus weekly Deltaprim $(\mathrm{n}=208)$, or (d) daily placebo plus weekly placebo $(n=207)$. There was no effect of iron supplementation on the frequency 
of malaria ( 0.87 vs. 1.00 cases per person-year; a protective effect of $12.8 \%$ in the iron-supplemented group). The authors concluded that iron supplementation given in doses and for a time adequate to replenish iron stores does not increase susceptibility to malaria in infants. Two other recently published studies, which used a low daily dose of iron, both showed no negative impact of iron supplementation on malaria $[120,121]$. In one of these studies, in Togo, daily oral iron $(2 \mathrm{mg} / \mathrm{kg})$ was administered for 3 months to children 6-36 months old who were followed closely during supplementation and for 6 months thereafter [120]. Mebrahtu et al. conducted a factorial trial in Zanzibar that included 614 children, aged 4-71 months, who were randomized to receive a daily oral dose of $10 \mathrm{mg}$ iron $(n=307)$ or placebo $(n=307)$, and 500 mg mebendazole or placebo every 3 months for 12 months [121]. The authors of both studies concluded from the lack of significant differences in morbidities between the treatment and control groups that low dose daily oral iron was not associated with a risk for increased prevalence of parasitemia or clinical malaria episodes. However, the two studies were not sufficiently powered to evaluate the safety of the supplement with respect to hospital admissions or death. For example, in the Togo study by Berger et al. [120], the sample size was relatively small ( $\mathrm{n}=100$ in the iron group and $\mathrm{n}=97$ in the placebo group) and it dropped differentially by $17 \%$ over the trial, making it difficult to draw conclusions with confidence from this study. In the study by Mebrahtu et al. [121], malarial parasitemia was assessed at monthly intervals with different sub-samples of children in alternative months. This could have led to missing some infections and therefore biased the results.

A review of 13 (nine published and four unpublished) randomized placebo-controlled supplementation trials suggests that the known benefits of iron supplementation are likely to outweigh the risk of adverse effects in regions with endemic malaria [122]. This presupposes that supplementation with iron should still continue even in areas where malaria is prevalent.

\section{Combined Iron and Zinc Supplementation in Malaria-Endemic Areas}

There have been two studies of combined iron and zinc supplementation in malaria-endemic regions [123, 124]. A study of children aged 6 months to 15 years in the Peruvian Amazon found that iron supplementation increased morbidity due to $P$. vivax; there were too few episodes of falciparum malaria to evaluate the impact of iron on P. falciparum [124]. Among children less than 5 years old, zinc, both alone and in combination with iron, was protective against $P$. vivax. This protective effect was not found in older children.

However, a recent study by Sazawal et al. [123], assessing the effect of iron and folic acid supplementation on severe morbidity and mortality from malaria in Tanzania, has raised additional concerns about the safety of iron supplementation in children in malaria-endemic areas. Children below 3 years were recruited into a clusterrandomized, double-masked, placebo-controlled trial. Enrolled children were randomized to iron plus folic acid; iron plus folic acid plus zinc; zinc, or placebo, and were followed up for about 1 year. The Tanzanian study provided $12.5 \mathrm{mg}$ iron and $50 \mu \mathrm{g}$ folic acid; children aged 1-11 months were provided only half of the dose. Children who received iron and folic acid with or without zinc were $12 \%(95 \%$ CI $2-23, p=0.02)$ more likely to die or need treatment in hospital for an adverse event and $11 \%$ $(1-23 \%, p=0.03)$ more likely to be admitted to the hospital; there were also $15 \%(p=0.19)$ more deaths in these groups. The analyses of cause-specific admissions to hospital and deaths confirmed that malaria and other infectious diseases were significantly increased in children given iron and folic acid. Results from a sub-study within this trial also suggested that only children who were irondeficient by zinc protoporphyrin assessment or who had moderate anemia at baseline had significantly lower rates of adverse events. This large well-designed study has several important implications. First, it adds further evidence to the literature suggesting that iron supplementation may be harmful for children in malaria-endemic areas. In contrast to the possible harmful role of iron, a negative interaction between the folic acid supplement and SP for malaria treatment is an alternative potential explanation for the increased rates of adverse events seen in the iron plus folic acid group (please see below for more information on the effect of folate on the efficacy of antimalarial drugs whose mechanism involves antifolate activity). Second, instead of universal iron supplementation, it might be safer to identify and treat anemia caused by iron deficiency with iron and folic acid in malaria-endemic areas. However, this presents programmatic challenges as it will not be easy to screen for iron deficiency before implementing a supplementation program because of the probable high cost involved. Hence on a population basis, more research is needed to identify the ultimate strategy for iron supplementation in malaria-endemic areas. 


\section{Folate}

During malaria infection, the malaria parasite induces a decline in host folate status through increased red cell degradation $[125,126]$ and increased utilization of folate [127]. Several in vitro and in vivo studies have also shown that folate is critical for the replication, growth and survival of the malarial parasite [128] and this folate requirement is met through de novo synthesis from exogenous folate added into the growth medium $[129,130]$. These observations suggest that host folate deficiency may protect against malaria. In fact, survival of the malaria parasite was hampered in folate-deficient rhesus monkeys [131].

In humans, the effect of folate status on parasite replication is still not clearly defined. Fleming and Werblinska [125] reported high rates of malaria in individuals with megaloblastic anemia. Hamilton et al. [132] reported low rates of infection in pregnant women consuming a folate-rich diet. The main public health concern, however, is whether folate supplementation enhances malaria parasite proliferation and worsens malaria outcomes through its interaction with antimalarial drugs. This is important because interfering with malaria parasite metabolism by depriving the parasite of folate is the mechanism of action for several drugs including SP and pyrimethamine-dapsone [133]. These drugs act by inhibiting the activity of enzymes of folate metabolism (dihydrofolate reductase and dihydropteroate synthetase) with the aim of blocking DNA synthesis and halting parasite growth.

\section{Impact of Folic Acid Supplementation on Malaria} Treatment

A small number of studies have looked at the interaction between supplemental folic acid and SP when used together in the management of children with acute malaria. In a study in The Gambia, concurrent treatment with SP and folic acid (5 mg/day) resulted in a higher treatment failure rate by day 14 in young children [134]. Another trial involving preschool children in The Gambia showed no adverse effects for malaria when prophylactic folate supplementation was given with antimalarial therapy [135]. In Kenya, subjects with clinical malaria (mean age 80 months) who received $2.5-5 \mathrm{mg}$ folic acid at the time of treatment with SP cleared parasites more slowly than patients in the control group during the first week after treatment, but the rate of parasite clearance became similar in the two groups after sometime and folic acid treatment did not effect the clinical cure rate for malaria [136]. Similar results were obtained in a Zambian study where children with acute malaria were treated with SP and a daily dose of folic acid [137]. The prevalence of parasitemia was significantly higher in those who had daily supplementation with $1 \mathrm{mg}$ folic acid/day than in those who received placebo at day 3 after the start of treatment but not at days 14 or 28 .

Overall, these data suggest that routine use of folate supplements in malarious areas is unlikely to exacerbate malaria. However, the use of higher amounts of folic acid in combination with antimalarial drugs whose mechanism of action is to interfere with folate metabolism in the malaria parasite may slightly impair the action of these drugs.

\section{Thiamine}

Malaria increases glucose metabolism thereby precipitating the deficiency of thiamine through its increased utilization [138]. Prolonged deficiency of thiamine results in beriberi, a clinical condition characterized by increased lactic acid accumulation or lactic acidosis. Lactic acidosis is a significant complication of severe malaria [139] and thiamine deficiency has been demonstrated in some studies as a risk factor for both complicated and uncomplicated malaria. Krishna et al. [140] demonstrated that thiamine deficiency commonly complicates acute falciparum malaria in adults in Thailand. In this study, adults presenting with malaria had more thiamine deficiency than controls and individuals with severe malaria had more thiamine deficiency than those with uncomplicated malaria. In a more recent study in Laos [141], 30\% of patients ( $>1$ year of age) presenting with uncomplicated $P$. falciparum malaria had biochemical evidence of thiamine deficiency (red cell transketolase activity $\geq 1.25$ ) and $12 \%$ had severe biochemical deficiency. These results suggest thiamine deficiency as a risk factor for both uncomplicated and severe malaria. However, more research is needed to confirm these results and to assess the use of thiamine as an adjunctive therapy for malaria treatment.

\section{Vitamin E}

Vitamin E has been implicated in the clinical course of malaria in both animals and humans. Several animal studies have reported protection against malaria when a vitamin E-deficient diet is fed to mice [142-146]. The first 
study in this area was by Godfrey [146] in 1957, who observed that a vitamin E-deficient diet containing cod-liver oil inhibited the growth of $P$. berghei and that this potent antiparasitic action was reversed when vitamin $\mathrm{E}$ was added to the diet. Levander et al. [142-144] made similar observations in three separate studies in which a vitamin E-deficient diet containing fish oil decreased malaria parasitemia in mice. In one of these studies, a vitamin E-deficient diet with 5\% cod-liver oil exhibited a strong antimalaria activity against $P$. yoelii to the extent that no additional benefit of an antimalarial drug (qinghaosu) could be demonstrated when this drug and the diet were given concurrently [142]. In another experiment, a vitamin E-deficient diet containing 5\% menhaden oil offered protection against CQ-sensitive and CQresistant Plasmodium parasites [143].

Results of a limited number of human studies reflect the inverse relationship between vitamin $\mathrm{E}$ status and malaria. The recrudescence of malaria upon feeding famine-affected Somali nomads observed by Murray et al. [35] was attributed to the consumption of cereal grains of high vitamin E content, although this was not confirmed in experimental studies. However, the reason for this hypothesis was that the occurrence of severe malaria was restricted to nomad children who ate grains whereas children who subsisted exclusively on milk were free from such a complication [147]. Some studies have monitored plasma vitamin E levels in malaria patients presenting to a hospital. These studies have shown that malaria patients who present with low serum vitamin E concentrations recover more quickly from clinical malaria episodes than their respective controls [148, 149].

The antioxidant property of vitamin $\mathrm{E}$ is considered the main mechanism behind the antimalaria effects of vitamin E deficiency. Highly reactive oxygen species, produced by immune response to malaria infection, have been shown to kill intra-erythrocyte malaria parasites in both in vitro and in vivo studies [150,151]. Vitamin E, on the other hand, protects body tissues from oxidative damage by removing oxygen free radicals that arise from metabolic reactions in the body. This suggests that a deficiency of antioxidants such as vitamin E could be protective against malaria by increasing the vulnerability of the parasite to free radical attack.

However, some human studies have shown that total serum $\alpha$-tocopherol is decreased in malaria patients relative to that of healthy controls [152]. However the decrease in serum $\alpha$-tocopherol does not mean that the subject is necessarily vitamin E-deficient, since this decrease
Table 3. Potential impact of micronutrient deficiencies on malaria

\begin{tabular}{|c|c|c|}
\hline $\begin{array}{l}\text { Micro- } \\
\text { nutrient }\end{array}$ & Effect & Hypothesized mechanism \\
\hline Vitamin A & Adverse & $\begin{array}{l}\text { Impaired immune function, increased } \\
\text { susceptibility to parasitemia, increased } \\
\text { malaria episodes and increased mor- } \\
\text { tality }\end{array}$ \\
\hline Zinc & Adverse & $\begin{array}{l}\text { Impaired immune function, increased } \\
\text { susceptibility to parasitemia, increased } \\
\text { malaria episodes and increased mor- } \\
\text { tality }\end{array}$ \\
\hline Iron & Protective & $\begin{array}{l}\text { Decreased susceptibility to parasit- } \\
\text { emia, impaired erythropoiesis, de- } \\
\text { creased malaria episodes, decreased } \\
\text { mortality }\end{array}$ \\
\hline Folate & Adverse & $\begin{array}{l}\text { Increased susceptibility to parasitemia, } \\
\text { increased malaria episodes, increased } \\
\text { mortality }\end{array}$ \\
\hline Vitamin E & Protective & $\begin{array}{l}\text { Decreased antioxidant activity, in- } \\
\text { creased parasite clearance by oxygen } \\
\text { radicals }\end{array}$ \\
\hline Thiamine & Adverse & $\begin{array}{l}\text { Increased plasma acidosis, increased } \\
\text { malaria complication }\end{array}$ \\
\hline Riboflavin & Unclear & $\begin{array}{l}\text { Decreased parasitemia but increased } \\
\text { morbidity in some studies }\end{array}$ \\
\hline Selenium & Not known & \\
\hline
\end{tabular}

could be due to the acute phase response to malaria infection. Davis et al. [148] observed an inverse association between plasma $\alpha$-tocopherol and biochemical indices of hepatic liver function in severe malaria patients, suggesting evidence of impaired release of vitamin $\mathrm{E}$ from the liver during malaria infection.

In summary, there is substantial evidence from animal models that vitamin E deficiency helps protect against malaria. While data from human studies are limited and complicated by difficulties interpreting vitamin E status in the setting of the acute phase response associated with malaria, there is nevertheless concern that vitamin E supplementation may exacerbate human malaria infections, although more human studies are needed in support of this claim. 


\section{Conclusions}

Malaria is a major cause of morbidity and mortality for children, especially those living in sub-Saharan Africa. While malaria episodes clearly have negative effects on the weight gain and linear growth of children, the impact of underlying malnutrition on the risk of acquisition of malaria and the severity of infection is complex.

During the last decade there has been a major shift towards the use of ACT for management of pediatric malaria, both uncomplicated and severe forms of the disease. This movement towards more effective, well-tolerated treatments for malaria has been complicated by issues with case management at the primary care level in rural settings of Africa and Asia. While treatment options have improved, there has also been increased energy put into improving methods for prevention. There appears to be a role for the use of certain micronutrients, especially vitamin A and zinc, for the prevention of malaria in young children (table 2). However, other essential vitamins such as vitamin $\mathrm{E}$ or folic acid may play potentially harmful roles by exacerbating malaria episodes or interfering with antimalarial therapy. Thus, although the use of multiple micronutrients would seem to be an ideal approach to enhancing the nutritional status of young children in malaria-endemic areas, more research is needed to determine the safety and efficacy of this approach.

\section{References}

1 Guerin PJ, Olliaro P, Nosten F, et al: Malaria: current status of control, diagnosis, treatment, and a proposed agenda for research and development. Lancet Infect Dis 2002;2: 564-573.

$\checkmark 2$ Rowe AK, Rowe SY, Snow RW, et al: The burden of malaria mortality among African children in the year 2000. Int J Epidemiol 2006;35:691-704.

$>3$ Snow RW, Craig M, Deichmann U, Marsh K: Estimating mortality, morbidity and disability due to malaria among Africa's non-pregnant population. Bull World Health Organ 1999;77:624-640.

4 Snow RW, Trape JF, Marsh K: The past, present and future of childhood malaria mortality in Africa. Trends Parasitol 2001;17:593597.

$\checkmark 5$ Trape JF, Pison G, Preziosi MP, et al: Impact of chloroquine resistance on malaria mortality. CR Acad Sci III 1998;321:689-697.

-6 Zucker JR, Ruebush TK, Obonyo C, et al: The mortality consequences of the continued use of chloroquine in Africa: experience in Siaya, western Kenya. Am J Trop Med Hyg 2003; 68:386-390.

7 Korenromp E, Williams B, Gouws E, et al: Measuring trends in childhood malaria mortality in Africa: a new assessment of progress toward targets based on verbal autopsy. Lancet Infect Dis 2003;3:349-358.

$>8$ Greenwood B, Mutabingwa T: Malaria in 2002. Nature 2002;415:670-672.

$\checkmark 9$ Snow RW, Guerra CA, Noor AM, et al: The global distribution of clinical episodes of Plasmodium falciparum malaria. Nature 2005;434:214-217.

10 Breman JG: The ears of the hippopotamus: manifestations, determinants, and estimates of the malaria burden. Am J Trop Med Hyg 2001;64:1-11.
-11 Greenwood BM, Bradley AK, Greenwood AM, et al: Mortality and morbidity from malaria among children in a rural area of The Gambia, West Africa. Trans R Soc Trop Med Hyg 1987;81:478-486.

12 Trape JF, Zoulani A, Quinn TC: Assessment of the incidence and prevalence of clinical malaria in children exposed to intense and perennial transmission. Am J Epidemiol 1987;126:193-201.

13 Steketee RW, Nahlen BL, Parise ME, Menendez C: The burden of malaria in pregnancy in malaria-endemic areas. Am J Trop Med Hyg 2001;64:28-35.

14 Guyatt HL, Snow RW: Malaria in pregnancy as an indirect cause of infant mortality in sub-Saharan Africa. Trans R Soc Trop Med Hyg 2001;95:569-576.

15 Guyatt HL, Snow RW: Impact of malaria during pregnancy on low birth weight in sub-Saharan Africa. Clin Microbiol Rev 2004; 17:760-769.

16 Steketee RW, Wirima JJ, Bloland PB, et al: Impairment of a pregnant woman's ability to limit Plasmodium falciparum by infection with human immunodeficiency virus type 1 . Am J Trop Med Hyg 1996;88:150-154.

17 Verhoeff FH, Brabin BJ, van Buuren S, et al: Increased prevalence of malaria in HIV-infected pregnant women and its implications for malaria control. Trop Med Int Health 1999;4:5-12.

18 World Health Organization: World Health Report. Geneva, WHO, 2002.

19 McCarthy D, Wolf H, Wu Y: Malaria and Growth. Working Paper. Washington, World Bank, 1999.

20 Gallup J, Sachs J: The Economic Burden of Malaria. Working Paper 52. Cambridge, Center for International Development, Harvard University, 2000.
21 World Health Organization: Guidelines for the Treatment of Malaria. Geneva, WHO, 2006. WHO/HTM/MAL/2006.1108.

22 World Health Organization: Severe falciparum malaria. Trans R Soc Trop Med Hyg 2000;94(suppl 1):S1-S90.

23 Marsh K, Forster D, Waruiru C, et al: Indicators of life-threatening malaria in African children. N Engl J Med 1995;332:13991404.

24 Mockenhaupt FP, Ehrhardt S, Burkhardt J, et al: Manifestation and outcome of severe malaria in children in northern Ghana. Am J Trop Med Hyg 2004;71:167-172.

25 Tripathy R, Parida S, Das L, et al: Clinical manifestations and predictors of severe malaria in Indian children. Pediatrics 2007;12: e454-e460.

26 McGregor IA: Malaria: nutritional implications. Rev Infect Dis 1982;4:798-804.

27 Marsden PD: The Sukuta Project. A longitudinal study of health in Gambian children from birth to 18 months of age. Trans R Soc Trop Med Hyg 1964;58:455-489.

28 Rowland MG, Cole TJ, Whitehead RG: A quantitative study into the role of infection in determining nutritional status in Gambian village children. Br J Nutr 1977;37:441450 .

29 McGregor IA, Gilles HM, Walters JH, Davies $\mathrm{AH}$ : Effects of heavy and repeated malaria infections on Gambian infants and children. Effects of erythrocyte parasitization. Br Med J 1956;2:686-692.

30 Nyakeriga AM, Troye-Blomberg M, Chemtai $\mathrm{AK}$, et al: Malaria and nutritional status in children living on the coast of Kenya. Am J Clin Nutr 2004;80:1604-1610. 
-31 Bradley-Moore AM, Greenwood BM, Bradley $\mathrm{AK}$, et al: Malaria chemoprophylaxis with chloroquine in young Nigerian children. III. Its effect on nutrition. Ann Trop Med Parasitol 1985;79:575-584.

32 ter-Kuile FO, Terlouw DJ, Kariuki S, et al: Impact of permethrin-treated bed nets on malaria, anemia, and growth in infants in an area of intense perennial malaria transmission in western Kenya. Am Soc Trop Med Hyg 2003;68(suppl 4):68-77.

-33 Snow RW, Molyneux CS, Njeru EK, et al: The effects of malaria control on nutritional status in infancy. Acta Trop 1997;65:1-10.

34 Archibald HM, Bruce-Chwatt LJ: Suppression of malaria with pyrimethamine in Nigerian school children. Bull World Health Organ 1956;15:775-784.

- 35 Murray MJ, Murray AB, Murray NJ, Murray MB: Diet and cerebral malaria: the effect of famine and refeeding. Am J Clin Nutr 1978; 31:57-61.

- 36 Edington G: Cerebral malaria in the Gold Coast African: four autopsy reports. Ann Trop Med Parasitol 1954;48:300-306.

- 37 Hendrickse RG, Hasan AH, Olumide LO, Akinkunmi A: Malaria in early childhood. An investigation of five hundred seriously ill children in whom a 'clinical' diagnosis of malaria was made on admission to the children's emergency room at University College Hospital, Ibadan. Ann Trop Med Parasitol 1971;65:1-20.

- 38 Murray MJ, Murray NJ, Murray AB, Murray MB: Refeeding malaria and hyperferraemia. Lancet 1975;1:653-654.

-39 Murray MJ, Murray AB, Murray MB, Murray CJ: Somali food shelters in the Ogaden famine and their impact on health. Lancet 1976;1:1283-1285.

-40 Murray MJ, Murray AB, Murray MB, Murray $C J$ : The adverse effect of iron repletion on the course of certain infections. Br Med J 1978;2:1113-1115.

41 Ahmad SH, Moonis R, Shahab T, et al: Effect of nutritional status on total parasite count in malaria. Indian J Pediatr 1985;52:285288.

\$2 Olumese PE, Sodeinde O, Ademowo OG, Walker O: Protein energy malnutrition and cerebral malaria in Nigerian children. J Trop Pediatr 1997;43:217-219.

43 Genton B, Al Yaman F, Ginny M, et al: Relation of anthropometry to malaria morbidity and immunity in Papua New Guinean children. Am J Clin Nutr 1998;68:734-741.

44 el Samani FZ, Willett WC, Ware JH: Nutritional and socio-demographic risk indicators of malaria in children under five: a cross-sectional study in a Sudanese rural community. J Trop Med Hyg 1987;90:6978.

45 Mbago MCY, Namfua PP: Some determinants of nutritional status of one to four year old children in low-income urban areas of Tanzania. J Trop Pediatr 1991;38:299-306.
46 Renaudin P, Lombart JP: Anemia in infants less than 1 year old in Moundou, Chad: prevalence and etiology (in French). Med Trop (Mars) 1994;54:337-342.

-47 Tshikuka J, Gray-Donald K, Scott M, Olela KN: Relationship of childhood protein-energy malnutrition and parasite infections in an urban African setting. Trop Med Int Health 1997;2:374-382.

48 Williams TN, Maitland K, Phelps L, et al: Plasmodium vivax: a cause of malnutrition in young children. QJM 1997;90:751-757.

49 Snow RW, Byass P, Shenton FC, Greenwood BM: The relationship between anthropometric measurements and measurements of iron status and susceptibility to malaria in Gambian children. Trans R Soc Trop Med Hyg 1991;85:584-589.

50 Shankar AH: Nutritional modulation of malaria morbidity and mortality. J Infect Dis 2000;182(suppl 1):S37-S53.

51 Moody A: Rapid diagnostic tests for malaria parasites. Clin Microbiol Rev 2002;15:6678.

52 Bell D, Wongsrichanalai C, Barnwell JW: Ensuring quality and access for malaria diagnosis: how can it be achieved? Nat Rev Microbiol 2006;4(suppl):S7-S20.

53 Gove S: Integrated management of childhood illness by outpatient health workers: technical basis and overview. Bull World Health Organ 1997;75(suppl 1):7-24.

54 Amexo M, Tolhurst R, Barnish G, Bates I: Malaria misdiagnosis: effects on the poor and vulnerable. Lancet 2004;364:18961898.

55 Reyburn H, Mbatia R, Drakeley C, et al: Overdiagnosis of malaria in patients with severe febrile illness in Tanzania: a prospective study. BMJ 2004;329:1212.

56 Perkins BA, Zucker JR, Otieno J, et al: Evaluation of an algorithm for integrated management of childhood illness in an area of Kenya with high malaria transmission. Bull World Health Organ 1997;75(suppl 1):33-42.

57 Kilian AH, Kabagambe G, Byamukama W, et al: Application of the ParaSight-F dipstick test for malaria diagnosis in a district control program. Acta Trop 1999;72:281-293.

58 Hamer DH, Ndhlovu M, Zurovac D, et al: Does improving coverage of parasitological diagnostic tests change malaria treatment practices? An operational cross-sectional study in Zambia. JAMA 2007;297:22272231.

59 Reyburn H, Mbakilwa H, Mwangi R, et al: Rapid diagnostic tests compared with malaria microscopy for guiding outpatient treatment of febrile illness in Tanzania: randomised trial. BMJ 2007;334:403.

60 White NJ: The treatment of malaria. N Engl J Med 1996:335:800-806.

61 World Health Organization: Roll Back Ma- 75 Murphy GS, Basri H, Purnomo, et al: Vivax laria. Geneva, WHO, 2003.
62 Bloland PB, Kazembe PN, Oloo AJ, et al: Chloroquine in Africa: critical assessment and recommendations for monitoring and evaluating chloroquine therapy efficacy in sub-Saharan Africa. Trop Med Int Health 1998;3:543-552.

63 Hamer DH, MacLeod W, Addo-Yobo E, et al: Age, temperature, and parasite density predict chloroquine treatment failure in children with uncomplicated falciparum malaria. Trans R Soc Trop Med Hyg 2003;97: 422-428. malarial Treatment (EANMAT): The efficacy of antimalarial monotherapies, sulphdoxine-pyrimethamine and amodiaquine in East Africa: implications for sub-regional policy. Trop Med Int Health 2003;8:860867.

65 Nosten F, Brasseur P: Combination therapy for malaria: the way forward? Drugs 2002;62: 1315-1329.

66 Kremsner PG, Krishna S: Antimalarial combinations. Lancet 2004;364:285-294.

67 World Health Organization, Bosman A, Delacollette C, Olumese PE, Ret al: The Use of Antimalarial Drugs: Report of An Informal Consultation. Geneva, WHO, 2001.

68 Staedke SG, Mpimbaza A, Kamya MR, et al: Combination treatments for uncomplicated falciparum malaria in Kampala, Uganda: randomised clinical trial. Lancet 2004;364: 1950-1957.

69 Omari A, Preston C, Garner P: Artemetherlumefantrine for treating uncomplicated falciparum malaria. Cochrane Database Syst Rev 2002;(3):CD003125.

70 Rowe AK, Hamel MJ, Flanders WD, et al: Predictors of correct treatment of children with fever seen at outpatient health facilities in a rural Tanzanian district. Am J Epidemiol 2000;151:1029-1035.

71 Eriksen J, Tomson G, Mujinja PGM, et al: Assessing health worker performance in malaria case management of underfives at health facilities in a rural Tanzanian district. Trop Med Int Health 2007;12:52-61.

72 Zurovac D, Ndhlovu M, Rowe AR, et al: Treatment of paediatric malaria during a period of drug transition to artemether-lumefantrine in Zambia: cross-sectional study. BMJ 2005;331:734-737.

73 Zurovac D, Ndhlovu M, Sipilanyambe N, et al: Pediatric malaria case management with artemether-lumefantrine in Zambia: a longitudinal study of changing practice. Malar J 2007;6:31.

74 Zurovac D, Njogu J, Akhwale WS, et al: Translation of artemether-lumefantrine treatment policy into paediatric clinical practice: an early experience from Kenya. Trop Med Int Health 2008, in press.

malaria resistant to treatment and prophylaxis with chloroquine. Lancet 1993;341:96100
64 East African Network for Monitoring Anti- 
76 Falade C, Makanga M, Premji Z, et al: Efficacy and safety of artemether-lumefantrine (Coartem) tablets (six-dose regimen) in African infants and children with acute, uncomplicated falciparum malaria. Trans $\mathrm{R}$ Soc Trop Med Hyg 2005;99:459-467.

-77 Zinc Against Plasmodium (ZAP) Study Group: Effect of zinc on the treatment of Plasmodium falciparum malaria in children: a randomized controlled trial. Am J Clin Nutr 2002;76:805-812.

78 Duggan C, MacLeod W, Krebs NF, et al: Plasma zinc concentrations are depressed during the acute phase response in children with falciparum malaria. J Nutr 2005;135:802-807.

-79 South East Asian Quinine Artesunate Malaria Trial group: Artesunate versus quinine for treatment of severe falciparum malaria: a randomised trial. Lancet 2005;366:717-725.

-80 Karunajeewa HA, Manning L, Mueller I, et al: Rectal administration of artemisinin derivatives for the treatment of malaria. JAMA 2007;297:2381-2390.

-81 Bronzan RN, Taylor TE, Mwenechanya M, et al: Bacteremia in Malawian children with severe malaria: prevalence, etiology, HIV coinfection, and outcome. J Infect Dis 2007;195: 895-904.

-82 Treluyer JM, Roux A, Mugnier C, et al: Metabolism of quinine in children with global malnutrition. Pediatr Res 1996;40:558-563.

-83 Salako LA, Sowunmi A, Akinbami FO: Pharmacokinetics of quinine in African children suffering from kwashiorkor. Br J Clin Pharmacol 1989;28:197-201.

84 Pussard E, Barennes H, Daouda H, et al: Quinine disposition in globally malnourished children with cerebral malaria. Clin Pharmacol Ther 1999;65:500-510.

85 Breman JG: The ears of the hippopotamus: manifestations, determinants, and estimates of the malaria burden. Am J Trop Med Hyg 2001;64:1-11.

86 Prasad AS: Zinc deficiency. BMJ 2003;326: 409-410.

87 Shankar AH, Prasad AS: Zinc and immune function: the biological basis of altered resistance to infection. Am J Clin Nutr 1998; 68(suppl):447S-463S.

88 Bates CJ, Evans PH, Dardenne M, et al: A trial of zinc supplementation in young rural Gambian children. Br J Nutr 1993;69:243255.

89 Shankar AH, Genton B, Baisor M, et al: The influence of zinc supplementation on morbidity due to Plasmodium falciparum: a randomized trial in preschool children in Papua New Guinea. Am J Trop Med Hyg 2000;62: 663-669.

90 Muller O, Becher H, van Zweeden AB, et al: Effect of zinc supplementation on malaria and other causes of morbidity in West African children: randomised double blind placebo controlled trial. BMJ 2001;322:1-5.
-91 Zinc Investigators' Collaborative Group: Prevention of diarrhea and pneumonia by zinc supplementation in children in developing countries: pooled analysis of randomized controlled trials. J Pediatr 1999; 135:689-697.

92 Zeba AN, Sorgho H, Rouamba N, et al: Major reduction of malaria morbidity with combined vitamin A and zinc supplementation in young children in Burkina Faso: a randomized double blind trial. Nutr J 2008;7:7.

$\$ 93$ Semba RD: The role of vitamin A and related retinoids in immune function. Nutr Rev 1998;56:S38-S48.

$\$ 94$ Villamor E, Fawzi WW: Vitamin A supplementation: implications for morbidity and mortality in children. J Infect Dis 2000; 182(suppl 1):S122-S133.

95 Davis TM, Skinner-Adams TS, Beilby J: In vitro growth inhibition of Plasmodium falciparum by retinol at concentrations present in normal human serum. Acta Trop 1998;69:111-119.

-96 Samba DC, Basco LK, Bleiberg-Daniel F, et al: Absence of effect of retinol on the in vitro development of Plasmodium falciparum. Int J Vitam Nutr Res 1992;62:99100.

97 Serghides L, Kain KC: Peroxisome proliferator-activated receptor gamma-retinoid $\mathrm{X}$ receptor agonists increase CD36-dependent phagocytosis of Plasmodium falciparum-parasitized erythrocytes and decrease malaria-induced TNF-alpha secretion by monocytes/macrophages. J Immunol 2001;166:6742-6748.

-98 Sturchler D, Tanner M, Hanck A, et al: A longitudinal study on relations of retinol with parasitic infections and the immune response in children of Kikwawila village, Tanzania. Acta Trop 1987;44:213-227.

99 Thurnham DI, Singkamani R: The acute phase response and vitamin A status in malaria. Trans R Soc Trop Med Hyg 1991;85: 194-199.

100 Friis H, Mwaniki D, Omondi B, et al: Serum retinol concentrations and Schistosoma mansoni, intestinal helminths, and malarial parasitemia: a cross-sectional study in Kenyan preschool and primary school children. Am J Clin Nutr 1997;66:665-671.

101 Filteau SM, Morris SS, Abbott RA, et al: Influence of morbidity on serum retinol of children in a community-based study in northern Ghana. Am J Clin Nutr 1993;58: 192-197.

102 Binka FN, Ross DA, Morris SS, et al: Vitamin A supplementation and childhood malaria in northern Ghana. Am J Clin Nutr 1995;61:853-859.

103 Hautvast JL, Tolboom JJ, West CE, et al: Malaria is associated with reduced serum retinol levels in rural Zambian children. Int J Vitam Nutr Res 1998;68:384-388.
104 Metzger A, Mukasa G, Shankar AH, et al: Antioxidant status and acute malaria in children in Kampala, Uganda. Am J Trop Med Hyg 2001;65:115-119.

105 Fawzi WW: Environmental factors that impact the efficacy of vitamin A supplements among children. Environ Nutr Interact 1997;1:299-333.

106 Flores H, Campos F, Araujo RC, Underwood BA: Assessment of marginal vitamin A deficiency in Brazilian children using the relative dose response procedure. Am J Clin Nutr 1984;40:1281-1289.

107 Shankar AH: Vitamin A and malaria. Am J Clin Nutr 1995;62:842-843.

108 Einterz EM, Bates ME: Fever in Africa: do patients know when they are hot? Lancet 1997;350:781-782.

-109 Shankar AH, Genton B, Semba RD, et al: Effect of vitamin A supplementation on morbidity due to Plasmodium falciparum in young children in Papua New Guinea: a randomised trial. Lancet 1999;354:203209.

110 Fawzi WW, Mbise RL, Hertzmark E, et al: A randomized trial of vitamin A supplements in relation to mortality among human immunodeficiency virus-infected and uninfected children in Tanzania. Pediatr Infect Dis J 1999;18:127-133.

111 Varandas L, Julien MR, Gomes A, et al: A randomized, double-blind, placebo controlled trial of vitamin A in severe malaria in hospitalized Mozambican children. Ann Trop Paediatr 2001;21:211-222.

112 Phillips RE, Looareesuwan S, Warrell DA, et al: The importance of anaemia in cerebral and uncomplicated falciparum malaria: role of complications, dyserythropoiesis and iron sequestration. Q J Med 1986;58: 305-323.

113 Brabin BJ: The role of malaria in nutritional anemias; in Fomon SJ, Slotkin S (eds): Nutritional Anemias. New York, Raven Press, 1992, pp 65-80.

114 Molyneux ME, Looareesuwan S, Menzies IS, et al: Reduced hepatic blood flow and intestinal malabsorption in severe falciparum malaria. Am J Trop Med Hyg 1989; 40:470-476.

-115 Masawe AE, Muindi JM, Swai GB: Infections in iron deficiency and other types of anaemia in the tropics. Lancet 1974;2:314317.

116 Oppenheimer SJ, Gibson FD, Macfarlane $\mathrm{SB}$, et al: Iron supplementation increases prevalence and effects of malaria: report on clinical studies in Papua New Guinea. Trans R Soc Trop Med Hyg 1986;80:603612.

117 Bates CJ, Powers HJ, Lamb WH, et al: Effect of supplementary vitamins and iron on malaria indices in rural Gambian children. Trans R Soc Trop Med Hyg 1987;81:286291. 
-118 Harvey PW, Heywood PF, Nesheim MC, et al: The effect of iron therapy on malarial infection in Papua New Guinean schoolchildren. Am J Trop Med Hyg 1989;40:1218.

119 Menendez C, Kahigwa E, Hirt R, et al: Randomised placebo-controlled trial of iron supplementation and malaria chemoprophylaxis for prevention of severe anaemia and malaria in Tanzanian infants. Lancet 1997;350:844-850.

120 Berger J, Dyck JL, Galan P, et al: Effect of daily iron supplementation on iron status, cell-mediated immunity, and incidence of infections in 6-36 month old Togolese children. Eur J Clin Nutr 2000;54:29-35.

-121 Mebrahtu T, Stoltzfus RJ, Chwaya HM, et al: Low-dose daily iron supplementation for 12 months does not increase the prevalence of malarial infection or density of parsites in young Zanzibari children. J Nutr 2004; 134:3037-3041.

-122 International Nutritional Anemia Consultative Group: Safety of iron supplementation programs in malaria-endemic regions. Acta Trop 2002;82:321-327.

123 Sazawal S, Black RE, Ramsan M, et al: Effects of routine prophylactic supplementation with iron and folic acid on admission to hospital and mortality in pre-school children in a high malaria transmission setting: community-based, randomised, placebo-controlled trial. Lancet 2006;367: 133-143.

124 Richard SA, Zavaleta N, Caulfield LE, et al: Zinc and iron supplementation and malaria, diarrhea, and respiratory infections in children in the Peruvian Amazon. Am J Trop Med Hyg 2006;75:126-132.

125 Fleming AF, Werblinska B: Anaemia in childhood in the Guinea savanna of Nigeria. Ann Trop Paediatr 1982;2:161-173.

- 126 Fleming AF, Hendrickse JP, Allan NC: The prevention of megaloblastic anaemia in pregnancy in Nigeria. J Obstet Gynaecol Br Commonw 1968;75:425-432.

-127 Brabin BJ, van den Berg H, Nijmeyer F: Folacin, cobalamin, and hematological status during pregnancy in rural Kenya: the influence of parity, gestation, and Plasmodium falciparum malaria. Am J Clin Nutr 1986; 43:803-815.

128 Peters W: Chemotherapy and Drug Resistance in Malaria. London, Academic Press, 1997.
129 Krungkrai J, Webster HK, Yothavong Y: De novo and salvage biosynthesis of pteroylpentaglutamates in the human malaria parasite, Plasmodium falciparum. Mol Biochem Parasitol 1989;32:25-37.

130 Stokstad ELR, Koch J: Folic acid metabolism. Physiol Rev 1967;47:83-116.

131 Das KC, Virdi JS, Herbert G: Survival of the dietarily deprived: folate deficiency protects against malaria in primates. Blood 1992;80:281a.

132 Hamilton PJ, Gebbie DA, Wilks NE, Lothe F: The role of malaria, folic acid deficiency and haemoglobin AS in pregnancy at $\mathrm{Mu}$ lago Hospital. Trans R Soc Trop Med Hyg 1972;66:594-602.

133 Gregson A, Plowe CV: Mechanisms of resistance of malaria parasites to antifolates. Pharmacol Rev 2005;57:117-145.

134 van Hensbroek MB, Morris-Jones S, Meisner S, et al: Iron, but not folic acid, combined with effective antimalarial therapy promotes haematological recovery in African children with acute falciparum malaria. Trans R Soc Trop Med Hyg 1995;89:672676.

135 Fuller NJ, Bates CJ, Hayes RJ, et al: The effects of antimalarials and folate supplements on haemtological indices and red cell folate levels in Gambian children. Ann Trop Paediatr 1988;8:61-67.

136 Carter JY, Loolpapit M, Lema OE, et al: Folic acid supplementation reduces the efficacy of antifolate antimalarial activity. Am J Trop Med Hyg 2005;73:166-170.

137 Mulenga M, Malunga F, Bennett S, et al: A randomised, double-blind, placebo-controlled trial of atovaquone-proguanil vs. sulphadoxine-pyrimethamine in the treatment of malarial anaemia in Zambian children. Trop Med Int Health 2006;11:16431652.

138 Mayxay M, Taylor AM, Khanthavong M, et al: Thiamin deficiency and uncomplicated falciparum malaria in Laos. Trop Med Int Health 2007;12:363-369.

139 Mayxay M, Pukritrayakamee S, Chotivanich $K$, et al: Identification of cryptic coinfection with Plasmodium falciparum in patients presenting with vivax malaria. Am J Trop Med Hyg 2001;65:588-592.

140 Krishna S, Taylor AM, Supanaranond W, et al: Thiamine deficiency and malaria in adults from southeast Asia. Lancet 1999; 353:546-549.

-141 Mayxay M, Chotivanich K, Pukrittayakamee $S$, et al: Contribution of humoral immunity to the therapeutic response in falciparum malaria. Am J Trop Med Hyg 2001; 65:918-923.
142 Levander OA, Ager ALJ, Morris VC, May RG: Qinghaosu, dietary vitamin E, selenium, and cod-liver oil: effect on the susceptibility of mice to the malarial parasite Plasmodium yoelii. Am J Clin Nutr 1989;50: 346-352.

143 Levander OA, Ager ALJ, Morris VC, May RG: Menhaden-fish oil in a vitamin E-deficient diet: protection against chloroquineresistant malaria in mice. Am J Clin Nutr 1989;50:1237-1239.

144 Levander OA, Ager AL Jr, Morris VC, May RG: Plasmodium yoelii: comparative antimalarial activities of dietary fish oils and fish oil concentrates in vitamin E-deficient mice. Exp Parasitol 1990;70:323-329.

145 Fevang P, Saav H, Hostmark AT: Dietary fish oils and long-term malaria protection in mice. Lipids 1995;30:437-441.

146 Godfrey DG: Antiparasitic action of dietary cod liver oil upon Plasmodium berghei and its reversal by vitamin E. Exp Parasitol 1957;6:555-565.

147 Edirisinghe JS: Infections in the malnourished: with special reference to malaria and malnutrition in the tropics. Ann Trop Paediatr 1986;6:233-237.

148 Davis TM, Binh TQ, Danh PT, et al: Serum vitamin $\mathrm{A}$ and $\mathrm{E}$ concentrations in acute falciparum malaria: modulators or markers of severity? Clin Sci 1994;87:505-511.

149 Eaton JW, Eckman JR, Berger E, Jacob HS: Suppression of malaria infection by oxidant-sensitive host erythrocytes. Nature 1976;264:758-760.

150 Clark IA, Hunt NH: Evidence for reactive oxygen intermediates causing hemolysis and parasite death in malaria. Infect Immun 1983;39:1-6.

151 Wozencraft AO, Dockrell H, Tarvern J, et al: Killing of human malaria parasites by macrophage secretory products. Infect Immun 1984;43:664-669.

152 Adelekan DA, Adeodu OO, Thurnham DI: Comparative effects of malaria and malnutrition on plasma concentrations of antioxidant micronutrients in children. Ann Trop Paediatr 1997;17:223-227.

153 Gilbert DN, Moellering RC, Eliopoulos GM, Sande MA: The Sanford Guide to Antimicrobial Therapy, ed 36. Sperryville, Antimicrobial Therapy, 2007. 